\title{
Investigation of Chitosan-PVA Composite Films and Their Adsorption Properties
}

\author{
Lewis S. Casey, Lee D. Wilson* \\ Department of Chemistry, University of Saskatchewan, Saskatoon, Saskatchewan, Canada \\ Email: ${ }^{*}$ lee.wilson@usask.ca
}

Received March 2015

\begin{abstract}
Viscous aqueous solutions of chitosan and polyvinyl alcohol (PVA) were blended to enhance miscibility and avoid polymer phase separation. The mixtures were drop-casted and air dried to yield composite film materials that were characterized by equilibrium water uptake, physical stability in aqueous solution, and thermal stability. Chitosan/PVA blends have greater thermal stability, unique morphology, and reduced solubility in acidic solution, thus extending the useful $\mathrm{pH}$ range for chitosan as a sorbent material. The uptake properties of the films was investigated using methylene blue (MB) and a p-nitrophenol (PNP) dyes, where it was found that each single component polymer has greater uptake toward MB than PNP. A direct relationship between film composition (chitosan:PVA) with solution $\mathrm{pH}$ and the uptake of MB was observed. The results are in agreement with electrostatic interactions and contributions due to the hydrophobic effect for such composite materials.
\end{abstract}

\section{Keywords}

Chitosan, Polyvinyl Alcohol, Methylene Blue, p-Nitrophenol, Sorption Properties, Composite Films

\section{Introduction}

This study aims to investigate binary chitosan and PVA composite polymer films and their adsorptive properties toward two types of organic dye molecules from aqueous solutions. We report the preparation of chitosan/PVA composite films with enhanced properties for the selective sorption of environmental contaminants from aqueous solutions. Their utility for environmental remediation or monitoring applications is proposed due to their versatile mechanical properties and ability to cast into various shapes. Chitosan is a linear polysaccharide composed of $\alpha$-1,4-linked D-glucosamine units, with a variable acetylation of the amine groups depending on the mode of preparation and isolation from chitin [1] [2]. Apart from environmental science applications, chitosan is an emerging green biomaterial with diverse applications in biotechnology, pharmacology, and medicine due to its unique physicochemical properties, including acid-base behavior, biodegradability, antimicrobial activity, and mucoadhesive nature [3]-[6]. Polyvinyl alcohol (PVA), is a synthetic thermoplastic with hydrophilic character [7] [8] with high tensile strength, elasticity, and moderate water solubility at elevated temperatures.

\footnotetext{
${ }^{*}$ Corresponding author.
}

How to cite this paper: Casey, L.S. and Wilson, L.D. (2015) Investigation of Chitosan-PVA Composite Films and Their Adsorption Properties. Journal of Geoscience and Environment Protection, 3, 78-84. 
PVA is biocompatible [3] [7] [8] and has been widely used for in vitro medical applications.

Composite blends of PVA and chitosan have been reported previously [4] [7]-[9]. Composite films offer advantages due to improvements in stability, biocompatibility, and mechanical strength relative to the properties of the single components [8]. The membrane permeability of binary blends between N-succinyl chitosan with PVA was reported [9] with similar sized organics [anionic benzenesulfonic acid (II), neutral styrene glycol, and cationic theophylline (III)) with variable ionization states. This contribution examines the adsorption properties of binary composite films containing chitosan and PVA by evaluating the uptake properties of composite films with two representative model organic dyes [methylene blue (MB) and $p$-nitrophenol (PNP)] at specific $\mathrm{pH}$ and concentration conditions. We anticipate that the results reported herein will contribute to a greater understanding of the adsorptive properties of such composite materials and extend the utility of such materials for sorptivebased applications.

\section{Experimental}

\subsection{Film Preparation}

Thin sheets of solid, flexible polymer were prepared by a solution casting method. Chitosan flakes (Sigma Aldrich, low molecular weight, $80 \%$ deacetylated) were dissolved in $4.6 \%(\mathrm{w} / \mathrm{w})$ acetic acid solution over $24 \mathrm{~h}$. The resulting gel was transparent and highly viscous. PVA (Sigma Aldrich, $146-186 \mathrm{kDa}$ ) was dissolved in water (milli-Q system) at $80^{\circ} \mathrm{C}$ with stirring to obtain a $5 \% \mathrm{w} / \mathrm{w}$ solution that was allowed to cool to room temperature. The solutions were combined in variable weight proportions to give the desired mass ratios of chitosan/PVA, and mechanically mixed using a small, high-torque rotary tool at $2000 \mathrm{rpm}$ for $10 \mathrm{~min}$. After blending, $0.50 \mathrm{~g}$ of each mixture, the mixture was transferred to Pyrex petri dishes ( 5 inch diameter) and allowed to air-dry at ambient conditions for 3 days. Dried films were then peeled from their dishes, and further dried at $50^{\circ} \mathrm{C}$ for 4 h. The films were cut into small squares ( 4 mm per side) and transferred into $200 \mathrm{~mL}(0.25 \mathrm{M})$ aqueous $\mathrm{NaOH}$ solution with occasional stirring for $2 \mathrm{~h}$. The films were removed and placed in two successive portions of fresh Millipore water $(200 \mathrm{~mL})$ for $15 \mathrm{~min}$. and $2 \mathrm{~h}$, respectively. Films were subsequently dried under vacuum for 12 $\mathrm{h}$ at $50^{\circ} \mathrm{C}$ and stored for future use in a desiccator.

\subsection{Swelling Tests}

The propensity of films to absorb water was measured gravimetrically. Dried film ( $\sim 50 \mathrm{mg})$ samples were immersed in distilled water for $20 \mathrm{~h}$. After removal from the water, the films were gently blotted on tissue paper (Fisher brand Delicate Task Wipers) to remove residual water, and reweighed. Experiments were performed in triplicate, and the mean results are reported.

\subsection{Thermogravimetric Analysis}

Films were cut into small $(\sim 5 \mathrm{mg})$ pieces and placed in aluminum pans for thermogravimetric analysis (TGA) on a TA Instruments Q-50. The temperature program was a linear ramp of $5^{\circ} \mathrm{C} \cdot \mathrm{min}^{-1}$ up to a final temperature of $500^{\circ} \mathrm{C}$. A nitrogen purge gas $\left(10 \mathrm{~mL} \cdot \mathrm{min}^{-1}\right)$ was used during the TGA heating profile.

\subsection{Degradation Tests}

The resistance of films was tested for dissolution in aqueous acid solution. Dried samples ( $20 \mathrm{mg}$ ) of film were placed in $2 \mathrm{~mL}(0.1 \mathrm{M} \mathrm{NaCl})$ adjusted to $\mathrm{pH} 1.6$ using $\mathrm{HCl}$. The vials were shaken horizontally at $2 \mathrm{~Hz}$ for $12 \mathrm{~h}$ prior to oven-drying at $50^{\circ} \mathrm{C}$ for $2 \mathrm{~h}$.

\subsection{Equilibrium Uptake Measurements}

The adsorption properties of films were evaluated using aqueous solutions of the model dyes MB and PNP. A 50 $\mathrm{mM} \mathrm{KH}_{2} \mathrm{PO}_{4}$ buffer at $\mathrm{pH} 5$ was prepared by adjusting the $\mathrm{pH}$ using an aqueous solution of $\mathrm{NaOH}$. A $50 \mathrm{mM}$ $\mathrm{NaHCO}_{3}$ buffer at $\mathrm{pH} 9.0$ was similarly prepared using $\mathrm{NaOH}$. The film samples $(60 \mathrm{mg})$ were transferred to 2 dram vials containing $3.00 \mathrm{~mL}$ of an aqueous dye solution: methylene blue $(20 \mu \mathrm{M})$ at $\mathrm{pH} 5.0$ or $9.0,100 \mu \mathrm{M}$ PNP (pH 5.0), or $33 \mu \mathrm{M}$ PNP (pH 9.0), respectively. The vials were sealed with an inert plastic film and shaken horizontally at $2 \mathrm{~Hz}$ for $24 \mathrm{~h}$. Incubated film solutions were then removed from the shaker and analyzed directly 
by UV-vis spectroscopy with quartz cuvettes. Samples were compared against an appropriate blank solution to give initial and equilibrium concentration values, denoted $\mathrm{C}_{0}$ and $\mathrm{C}_{\mathrm{e}}$, respectively. Beer-Lambert calibration plots of MB in aqueous solution yielded the following parameters: $\lambda_{\max }=660 \mathrm{~nm}\left(2.70 \times 10^{5} \mathrm{~mol}^{-1} \cdot \mathrm{L}^{-1} \cdot \mathrm{cm}^{-1}\right)$, $320\left(9.50 \times 10^{5} \mathrm{~mol}^{-1} \cdot \mathrm{L}^{-1} \mathrm{~cm}^{-1}\right)$, and $400\left(2.22 \times 10^{5} \mathrm{~mol}^{-1} \cdot \mathrm{L}^{-1} \cdot \mathrm{cm}^{-1}\right)$ for $\mathrm{MB}$, and both neutral and anion forms of PNP, respectively. Linear regression of the calibration plots yield the molar absorptivity of the dyes (MB or PNP) that allow estimation of the dye concentration before adsorption $\left(\mathrm{C}_{\mathrm{o}}\right)$ and after adsorption $\left(\mathrm{C}_{\mathrm{e}}\right)$ by the polymer films, according to Equation (1).

$$
\mathrm{Q}_{\mathrm{e}}=\frac{\left(\mathrm{C}_{\mathrm{o}}-\mathrm{C}_{\mathrm{e}}\right) \times \mathrm{V}}{\mathrm{m}}
$$

$\mathrm{Q}_{\mathrm{e}}$ is the quantity of adsorbate in the polymer phase adsorbed at equilibrium $\left(\mathrm{mg} \cdot \mathrm{g}^{-1}\right), \mathrm{C}_{\mathrm{o}}$ and $\mathrm{C}_{\mathrm{e}}$ are the adsorbate concentrations $\left(\mathrm{mg} \cdot \mathrm{L}^{-1}\right)$ in aqueous solution, $\mathrm{V}$ is volume of adsorbate solution, and $\mathrm{m}$ is mass $(\mathrm{g})$ of polymer film.

\section{Results and Discussion}

\subsection{Swelling Tests}

The level of swelling $(\% \mathrm{w} / \mathrm{w})$ of the polymer films was determined by the differences in weight $(\mathrm{Wt})$ of swollen films in the hydrated (swelled) versus the dry state, according to the Equation (2).

$$
\text { Swelling }(\%)=100 \% \times\left(\frac{\mathrm{Wt}_{\mathrm{wet}}-\mathrm{Wt}_{\mathrm{dry}}}{\mathrm{Wt}_{\mathrm{dry}}}\right)
$$

Table 1 lists the swelling data for neutralized films with variable composition. The results indicates that the PVA content of the composites contributes more significantly to swelling than chitosan. This observation is consistent with the greater hydrophilic character of PVA according to its overall water solubility. To determine the effect of neutralization of residual acetic acid in the films, a swelling test was performed on a 1:1 chitosan/PVA film that was not neutralized. By contrast, the non-neutralized film underwent rapid dissolution in an environment of distilled water over a period of 15 minutes at quiescent conditions. Such behavior reveals the importance of neutralization of chitosan on film solubility and stability towards polymer chain packing effects and infiltration of solvent into the micropore domains of the film materials.

\subsection{Stability Tests}

In addition to swelling tests, the resistance of neutralized films to dissolution in aqueous solution was studied at low $\mathrm{pH}$ conditions. Dried film samples were assessed for the degree of mass loss (w/w; \%) by Equation (3),

$$
\operatorname{Loss}(\%)=100 \% \times\left(\frac{\mathrm{Wt}_{\mathrm{i}}-\mathrm{Wt}_{\mathrm{f}}}{\mathrm{Wt}_{\mathrm{i}}}\right)
$$

where $\mathrm{Wt}_{\mathrm{i}}$ and $\mathrm{Wt}_{\mathrm{f}}$ are the dry film weights before and after equilibration in water at $\mathrm{pH}$ 1.6.

Data from Table 2 indicates that composite films have slightly greater stability as the PVA content increases. While PVA displays greater swelling in water, it does not dissolve unless higher temperature conditions $\left(>60^{\circ} \mathrm{C}\right)$ are used. Film stability is enhanced when the materials are properly neutralized with $\mathrm{NaOH}$, including single component chitosan films. This may be due to structural rearrangement of the composite, which occurs during neutralization of the protonated amine sites of chitosan, leading to an increase in packing efficiency of polymer segments and attenuated solubility, as reported by Ogawa et al. [10]. The change in morphology was related to restructuring from a hydrated (L-2 form) to the anhydrous crystalline form of chitosan. After treatment with $\mathrm{NaOH}$, rinsing, and drying, the films that contain chitosan are slightly shrunken and more brittle. TGA results confirm that acetic acid is eliminated by this treatment, and trace water is also removed, resulting in films with reduced wetting characteristics and dissolution in water. This behavior was previously investigated where it was concluded that the partial restructuring of chitosan from a hydrated phase to an anhydrous form is related to solubility [10] [11].

\subsection{Thermogravimetric Analysis}

In addition to the swelling and dissolution characteristics of film samples, the thermal stability of single-and 
Table 1. Results of film swelling in water at ambient conditions.

\begin{tabular}{ccc}
\hline $\begin{array}{c}\text { Film Composition } \\
\text { (chitosan/PVA) }\end{array}$ & $\begin{array}{c}\text { Neutralize } \\
\text { (to } \mathrm{pH} 7)\end{array}$ & $\begin{array}{c}\text { Swelling } \\
(\% \mathrm{w} / \mathrm{w})\end{array}$ \\
\hline $100: 0$ & Yes & $147 \% \pm 12 \%$ \\
$50: 50$ & Yes & $172 \% \pm 10 \%$ \\
$35: 65$ & Yes & $201 \% \pm 11 \%$ \\
$25: 75$ & Yes & $207 \% \pm 13 \%$ \\
$5: 95$ & Yes & $206 \% \pm 16 \%$ \\
$0: 100$ & Yes & $190 \% \pm 2 \%$ \\
$50: 50$ & No & Dissolves
\end{tabular}

Table 2. Degradative weight loss of film materials in aqueous solution (pH 2.0) at $298 \mathrm{~K}$.

\begin{tabular}{cc}
\hline Composition $\left(\mathrm{Ch}:\right.$ PVA) $^{\mathrm{a}}$ & Mass Loss (\%w/w) \\
\hline $100: 0$ & $5 \%$ \\
$50: 50$ & $1 \%$ \\
$35: 65$ & $2 \%$ \\
$25: 75$ & $<1 \%$ \\
$5: 95$ & $<1 \%$ \\
$0: 100$ & $<1 \%$ \\
\hline
\end{tabular}

${ }^{\mathrm{a}}$ Specifies whether residual acetic acid was present in film from preparation, or whether it was neutralized by treatment with $\mathrm{NaOH}$.

binary-component films were investigated using TGA. Previous work [12] [13] on chitosan copolymers revealed that the thermal stability of copolymers differed relative to pure chitosan. A chitosan film which had been neutralized in aqueous $\mathrm{NaOH}$ was compared with a film of similar composition which was washed repeatedly with distilled water.

The primary effect of film neutralization is evidenced by the elimination of residual acetic acid, which has a thermal event centered at $162^{\circ} \mathrm{C}$. This observation is consistent with elevated temperature loss profiles of water bound within micropore sites of microporous materials. By contrast, the event at $162^{\circ} \mathrm{C}$ is absent in the TGA results of the neutralized films ( $c f$. Figure 1). Acetic acid and water are anticipated to interact with polar domains or micropore sites due to their comparable size and polarity. The thermal events for vaporization of water and acetic acid are broad and shifted to higher temperature, suggesting that they are bound tightly within microporous domains [13] of the film. After neutralization with $\mathrm{NaOH}$, the thermal event for acetic acid is absent $\left(\sim 162^{\circ} \mathrm{C}\right)$ in the thermograms of Figure 2. The thermal event at $250^{\circ} \mathrm{C}-300^{\circ} \mathrm{C}$ attributed to chitosan decomposition is also shifted to higher temperature after neutralization, supporting the creation of a unique crystal phase after neutralization. In binary composite films (Figure 2), the stabilizing interactions between glucosamine units and intermolecular interactions with PVA aides in stabilizing the composite film [14]. The presence of chitosan and PVA results enhanced thermal stability, as evidenced by a new thermal event with a wider temperature range for mixed films between $320^{\circ} \mathrm{C}-375^{\circ} \mathrm{C}$, in agreement with Yang et al. [4]. Enhanced thermal stability of composite films may be due to H-bonding between components and improved packing of film components, as evidenced by the TGA results for crystalline and amorphous forms of chitosan [13].

\subsection{Dye Sorption}

Dye sorption has been employed to estimate the textural and sorptive properties of polysaccharide-based materials containing amylose [14] and chitosan [15]-[17]. The equilibrium uptake $\left(\mathrm{Q}_{\mathrm{e}}\right)$ of PNP and methylene blue was evaluated at fixed initial concentration conditions ( $c f$. Equation (1)). The dependence of $\mathrm{Q}_{\mathrm{e}}$ on the relative content of chitosan/PVA (w/w; \%) was evaluated on the basis of the adsorption properties of single and binary 


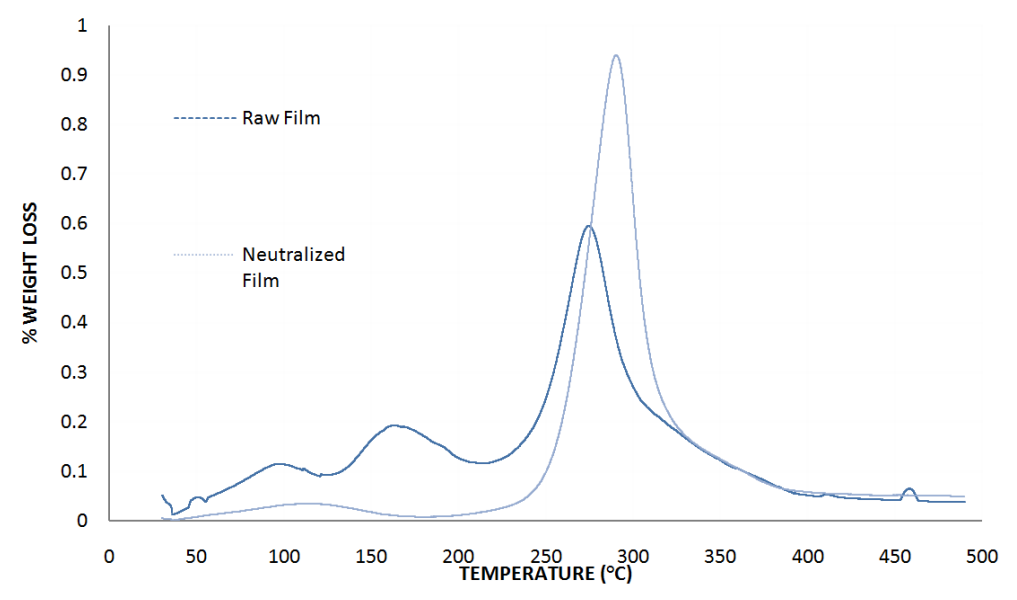

Figure 1. Derivative TGA plots of neutralized and non-neutralized chitosan films.

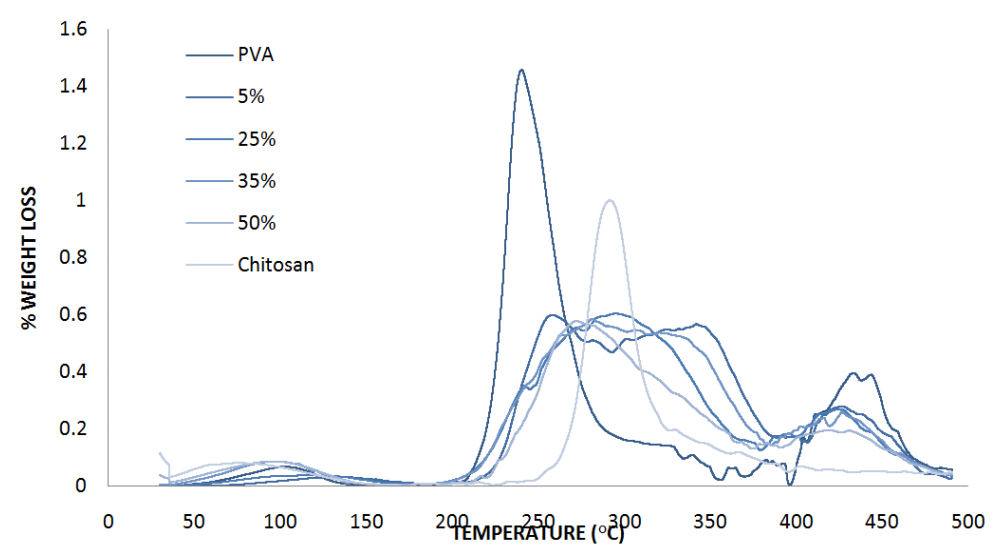

Figure 2. Derivative TGA plots of neutralized chitosan/PVA films.

component films.

Casted films reveal negligible uptake of PNP at pH 5.0 and $9.0(>1 \mathrm{mg} / \mathrm{g})$ films that contain chitosan are protonated near $\mathrm{pH} 5$ since this condition lies below the $\mathrm{pK}_{\mathrm{a}}(\sim 5.6)$ of pristine chitosan. Protonation of the amine sites of chitosan results in repulsive electrostatic interactions with attenuated sorptive uptake of PNP. By comparison, MB shows a clear trend in uptake according to the incremental chitosan content of the film at each $\mathrm{pH}$ condition. The binding affinity to films containing chitosan is attenuated at $\mathrm{pH} 5$ (below $\mathrm{pK}_{\mathrm{a}}$ of chitosan), in agreement with a positive zeta-potential at the surface, or within the film interior. Protonation of the amine group of chitosan $\left(\mathrm{pK}_{\mathrm{a}}=5.5\right)$ is anticipated to exert a repulsive electrostatic interaction with MB at these conditions [15]. The MB cation dye shows moderate binding to films of pure PVA, which can be viewed as more hydrophilic in nature with and electron rich domains suitable for binding with cation dyes. The interaction with $\mathrm{MB}$ is reversed at $\mathrm{pH} 9.0$, as evidenced by an attenuation of the uptake at low chitosan film composition, as seen in Figure 3. At elevated $\mathrm{pH}$, the screening of the formal charge of $\mathrm{MB}$ by hydroxide ions is anticipated at such alkaline $\mathrm{pH}$ conditions. Thus, the favourable uptake of $\mathrm{MB}$ at $\mathrm{pH} 5$ may be related to electrostatic attractions between the polar functional groups of chitosan and PVA that favours complementary interactions. That the composite exhibits a nonlinear trend in $\mathrm{Q}_{\mathrm{e}}$ vs chitosan composition (\%) suggests that cooperative or synergistic interactions may occur between each polymer segment. This could be due to macroscopic reorganization such as localization of chitosan at the film surface during the casting process, the cooperative generation of favourable binding sites between PVA and chitosan, or the steric disruption of favourable binding sites on one polymer by the second polymer component. Relative to single component systems, composite films have other advantages such as improved durability, improved thermal stability, and improved adsorption of mixed sorbates, eitherca- 


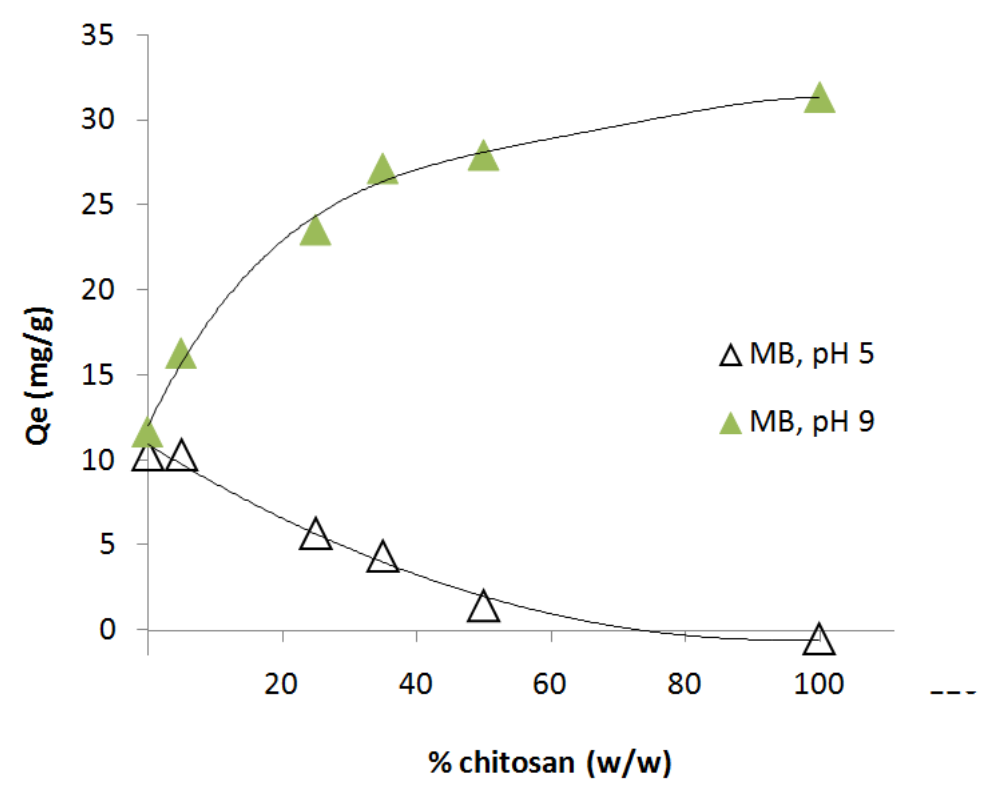

Figure 3. The effect of film composition (\% chitosan) on uptake toward methylene blue (MB) at variable solution $\mathrm{pH}$ at $298 \mathrm{~K}$, where $\mathrm{C}_{0}=20 \mu \mathrm{M}$.

tion and neutral forms. Chitosan-PVA films of the type described herein are anticipated to have useful applications as coatings in biomedical devices or advanced drug delivery systems due to their unique properties and stability [18]. Polymer blending of binary systems such as modified chitosan is currently under investigation to evaluate the role of porogens [19], physical and chemical cross-linking [4] [20], or complex formation [21] with metals or polyelectrolytes.

\section{Conclusions}

Composite polymer films of chitosan were prepared by blending and drop casting. Film characterization was done by swelling, dissolution, and TGA experiments. While chitosan and PVA undergo swelling, PVA displayed greater uptake in distilled water at neutral $\mathrm{pH}$ conditions; whereas, chitosan undergoes substantial swelling at $\mathrm{pH}$ conditions less than $\mathrm{pH} 5.5$ (i.e. $\mathrm{pH}<\mathrm{pK}_{\mathrm{a}}$ ). The reduced stability of chitosan in binary film composites at $\mathrm{pH}$ conditions near its $\mathrm{pK}_{\mathrm{a}}$ is anticipated due to strong hydration of the ammonium ions along the polymer backbone leading to favourable hydration and dissolution in water. Neutralized films showed markedly different physical, thermal, and solubility properties, as shown by their tunable solubility and enhanced stability of binary films with variable composition.

PNP showed negligible binding to all films regardless of $\mathrm{pH}$. The adsorption properties of binary composite films were reduced at low $\mathrm{pH}$ for the composite films due to protonation of chitosan as evidenced by electrostatic repulsion with the MB cationic dye at $\mathrm{pH}$ 5. By contrast, binary films enriched with chitosan show high MB uptake at $\mathrm{pH}$ 9. The blending of chitosan with PVA in films or other cast solid forms combines favourable affinity for cationic substrates with the good affinity of PVA for neutral adsorbates. These favourable attributes are extended by the improved mechanical and thermal properties of composite films and the resistance to breakdown in water offered by a facile reaction of a base in aqueous solution in a manner analogous to photochemical treatment of chitosan-based films [22]. The results presented herein provide evidence for the potential application of chitosan/PVA films as a tunable sorbent material for cationic pollutants and the potential application of such materials in environmental sensing devices, pollutant remediation or biomedical applications.

\section{Acknowledgements}

The authors would like to acknowledge, the University of Saskatchewan and Environment Canada through the Science Horizons Youth Employment Strategy (YES) program for support of this research(Project number: 01097760), and Dr. H. Mohamed for TGA analysis and support throughout the project. 


\section{References}

[1] Crini, G. and Badot, P. (2008) Application of Chitosan, a Natural Aminopolysaccharide, for Dye Removal from Aqueous Solutions by Adsorption Processes Using Batch Studies: A Review of Recent Literature. Progress in Polymer Science, 33, 399-447. http://dx.doi.org/10.1016/j.progpolymsci.2007.11.001

[2] Muzzarelli, R.A.A. (1973) Natural Chelating Polymers. Pergamon Press, Oxford.

[3] Sionkowska, A. (2011) Current Research on the Blends of Natural and Synthetic Polymers as New Biomaterials: Review. Progress in Polymer Science, 1254-1276. http://dx.doi.org/10.1016/i.progpolymsci.2011.05.003

[4] Yang, J.M., Su, W.Y., Leu, T.L., Lang, T. and Yang, M.C. (2004) Evaluation of Chitosan/PVA Blended Hydrogel Membranes. Journal of Membrane Science, 236, 39-51. http://dx.doi.org/10.1016/j.memsci.2004.02.005

[5] Park, C., Co, P., Park, J.W., Choi, K.-H. and Park, K.K. (1983) Acid-Base Equilibria and Related Properties of Chitosan. Bulletin of the Korean Chemical Society, 4, 68-72.

[6] Trung, T.S., Ng, C.-H. and Stevens, W.F. (2003) Characterization of Decrystallized Chitosan and Its Application in Biosorption of Textile Dyes. Biotechnology Letters, 25, 1185-1190. http://dx.doi.org/10.1023/A:1024562900548

[7] Costa-Júnior, E.S., Pereira, M.M. and Mansur, H.S. (2008) Properties and Biocompatibility of Chitosan Films Modified by Blending with PVA and Chemically Crosslinked. Journal of Materials Science: Materials in Medicine, 20, 553-561. http://dx.doi.org/10.1007/s10856-008-3627-7

[8] Rogovina, S.Z. and Vikhoreva, G.A. (2006) Polysaccharide-Based Polymer Blends: Methods of Their Production. Glycoconjugate Journal, 23, 611-618. http://dx.doi.org/10.1007/s10719-006-8768-7

[9] Hideto, M., Takashi, T. and Yoshiro, K. (1999) Permeability of Ionic Solutes in a Polyamphoteric Membrane. Separation and Purification Technology, 16, 181-187. http://dx.doi.org/10.1016/S1383-5866(99)00006-4

[10] Kozo, O., Toshifumi, Y. and Masaru, M. (1992) Dependence on the Preparationprocedure of Polymorphism and Crystallinity of Chitosanmembranes. Bioscience, Biotechnology, and Biochemistry, 56, 858-862. http://dx.doi.org/10.1271/bbb.56.858

[11] Rinaudo, M. (2006) Chitin and Chitosan: Properties and Applications. Progress in Polymer Science, 31, 603-632. http://dx.doi.org/10.1016/j.progpolymsci.2006.06.001

[12] Poon, L., Wilson, L.D. and Headley, J.V. (2014) Chitosan-Glutaraldehyde Copolymers and Their Sorption Properties. Carbohydrate Polymers, 109, 92-101. http://dx.doi.org/10.1016/j.carbpol.2014.02.086

[13] Wilson, L.D. and Xue, C. (2013) Macromolecular Sorbent Materials for Urea Capture. Journal of Applied Polymer Science, 128, 667-675. http://dx.doi.org/10.1002/app.38247

[14] Wilson, L.D., Mohamed, M.H. and Headley, J.V. (2011) Surface Area and Pore Structure Properties of Urethane-Based Copolymers Containing $\beta$-Cyclodextrin. Journal of Colloid and Interface Science, 357, 215-222. http://dx.doi.org/10.1016/j.jcis.2011.01.081

[15] Guo, R. and Wilson, L.D. (2012) Synthetically Engineered Chitosan-Based Materials and Their Sorption Properties with Methylene Blue in Aqueous solution. Journal of Colloid and Interface Science, 388, 225-234. http://dx.doi.org/10.1016/j.jcis.2012.08.010

[16] Pratt, D.Y., Wilson, L.D. and Kozinski, J.A. (2013) Preparation and Sorption Studies of Glutaraldehyde Cross-Linked Chitosan Copolymers. Journal of Colloid and Interface Science, 395, 205-211.

[17] Poon, L., Younus, S. and Wilson, L.D. (2014) Adsorption Study of an Organo-Arsenical with Chitosan-Based Sorbents. Journal of Colloid and Interface Science, 420, 136-144. http://dx.doi.org/10.1016/j.jcis.2014.01.003

[18] Djamourov, M., Nishinari, K. and Ross-Murphy, S.B. (2013) Physical Gels from Biological and Synthetic Polymers. Cambridge University Press, New York, 338-339. http://dx.doi.org/10.1017/CBO9781139024136

[19] Chao, A.-C., Yu, S.-H. and Chuang, G.-S. (2006) Using NaCl Particles as Porogen to Prepare a Highly Adsorbent Chitosan Membranes. Journal of Membrane Science, 280, 163-174. http://dx.doi.org/10.1016/j.memsci.2006.01.016

[20] He, G., Zheng, H. and Xiong, F. (2008) Preparation and Swelling Behavior of Physically Crosslinked Hydrogels Composed of Poly(vinyl alcohol) and Chitosan. Journal of Wuhan University of Technology (Materials Science Edition), 23, 816-820.

[21] Honary, S., Hoseinzadeh, B. and Shalchian, P. (2010) The Effect of Polymer Molecular Weight on Citrate Crosslinked Chitosan Films for Site-Specific Delivery of a Non-Polar Drug. Tropical Journal of Pharmaceutical Research, 6, 525531.

[22] Jawad, A.H. and Nawi, M.A. (2012) Characterizations of the Photocatalytically-Oxidized Cross-Linked ChitosanGlutaraldehdye and Its Applicationas a Sub-Layer in the $\mathrm{TiO}_{2} / \mathrm{CS}-\mathrm{GLA}$ Bilayer Photocatalyst System. Journal of Polymers and the Environment, 20, 817-829. http://dx.doi.org/10.1007/s10924-012-0434-5 